\title{
Chapter
}

\section{Therapeutic Landscapes: A Natural Weaving of Culture, Health and Land}

\author{
Bruno Marques, Jacqueline McIntosh and Hayley Webber
}

\begin{abstract}
Current concepts of therapeutic landscape combine landscape with principles of holistic health and the interaction of social, affective and material factors. As social tensions widen the gap between the places of emotional retreat and healing from those of everyday sociability, concepts of therapeutic landscape are evolving to reflect society's current values. This chapter examines how cultural placebased values affect and maintain physical, emotional, mental and spiritual health and well-being in the context of a therapeutic landscape. Five case studies from Australasia, Africa, Middle East and Latin America are analysed to understand better the interrelationships between land, culture and health that make an environment therapeutic. The case studies were selected based on their engagement with the cultural traditions of landscape architecture and how the boundaries of these cultural traditions are negotiated within a modern context. The chapter contributes to the knowledge base of landscape architects and academics interested in the role of culture in producing and maintaining therapeutic landscapes by presenting a cross-cultural analysis to illustrate a range of strategies for incorporating cultural traditions and customs into modern landscape architectural contexts to promote health and well-being.
\end{abstract}

Keywords: therapeutic landscapes, therapeutic environments, culture, health, well-being, Indigenous knowledge, landscape, landscape architecture

\section{Introduction}

It has always been known that humans find reassurance in nature. Therapeutic sanctuaries have been sought out through the ages by individuals who have a sense of disorientation or likely future ambiguity. For example, those diagnosed with acute and terminal illness often search for a space of solitude, needing time and space for reflection on significant life and health changes [1]. Explanations for this phenomenon find that the brain is capable of two types of attention: directed attention, belonging to the higher cognitive centres, and soft fascination, linked to the old parts of the brain [2]. In natural environments, the higher cognitive centres of the human brain can rest and reset, lending some of the first scientific evidence to the healing powers of nature.

Most recently, as social tensions associated with the Covid-19 pandemic, climate change and racial inequity deepen the need for places of emotional retreat and 
healing, therapeutic landscapes have become an increasing topic of interest [3, 4]. However, while more and more research [5-7] finds that contact with nature plays a critical role in psychological well-being, and for those in need, a faster recovery from psychological trauma or stress, Ulrich \& Gilpin found when researching hospital gardens, an example that had a measurable negative effect on patient's health [8]. Similarly, following an extensive review of healing gardens, Stigsdotter \& Grahn found that not all gardens are healing gardens [9], leading to the question, what is a therapeutic landscape or a healing garden?

The term therapeutic landscape was originally defined in 1992 by the geographer William Gesler as a place "where physical and built environments, social conditions and human perceptions combine to produce an atmosphere which is conducive to healing" [10]. This definition was contested, critiqued and elaborated on over the next two decades, extending from a literal relationship between health and place with the acknowledgment of extraordinary places to a much expanded and refined characterisation. The extended literature reflected the growing interest in the relational and situated approach to well-being, which acknowledged the therapeutic nature of places in the context of those social, cultural, material, affectional and sensual aspects of human and non-human factors [1]. Such therapeutic encounters are defined differently by others, such as 'networks' [11], 'experiences' and 'environments' [12], 'taskscapes' [13], 'mobilities' [14], 'assemblages' [15] and 'enabling places' [16], with the latter gaining particular purchase amongst health and cultural geographers alike.

This theoretical turn saw a much greater emphasis on qualitative and ethnographic methodologies in the study of health designed to reveal the histories, discourses, and lived experiences of a place. Building on the contention that different people experience therapeutic landscapes differently or at different times, the potential healing outcome of the landscape can be seen as a relational process, and therapeutic landscapes become socially and culturally responsive. People's behaviour is deeply embedded within a place, particularly around health [17]. It is not just the space that is healing but the intention of those using the space [18]. Places should not only be defined by the fact they are conducive to healing but also places that are conducive to the maintenance of health and well-being $[19,20]$.

Successful therapeutic spaces generally reflect a society's current values and aspirations, and as such, become part of its identity. Situated in the current context, 'place' becomes even more challenged and implies that such spaces may need to be flexible to changing interpretation to remain therapeutic over time. Foley \& Kistemann [21] considered therapeutic spaces as emergent through a set of embodied experiential practices linking affects, emotions, and bodily sense that arise from being immersed in such therapeutic environments. This form of assemblage can therefore be better understood through its material, metaphorical, and inhabited dimensions $[15,22]$. The material component would contain the tangible aspects of landscape that people experience due to their therapeutic qualities. The metaphorical component comprises the ethnographic and cultural values expressed through narratives, myths, and stories that are crucial in defining site-specific rituals and cures. Inhabitation brings together mind, body, and spirit because it draws from lived, experiential, and performative health dimensions.

To this concept, Andrews [17] proposed two streams of application. One relates to the impact of landscape on human experience. The other pertains to how therapeutic landscapes are shaped by the influence of different belief systems, leading to the cultural specificity of the therapeutic landscape concept. In this way, culture and requirements for health create an assemblage of layers that combine in bespoke combinations depending on the individual and the time. The implication is that a healing environment cannot be achieved by a set of design requirements or details 
you need to meet, it must facilitate a healthcare service that is patient-focused and centres on the diverse needs of all [23]. This extends the therapeutic landscape concept to encompass both tangible and intangible values, supporting the proposition that health, well-being, and place are intricately intertwined and emergent through the layering of architecture and material; with practices and responses in a narrative of individual and communal history where people are simply seeking well-being.

Indigenous methods of restoring health and well-being offer new opportunities for understanding the complexity of health and well-being. Most of the Western understanding around therapeutic landscapes has come from the healing properties of the physical space and adopting a bio-medical approach, translated into spas, mineral springs and mountain retreats [24]. For example, in areas of natural springs, much was made of the unique chemical make-up of the water until scientists uncovered the lack of chemical difference [11]. With this narrow view, what was overlooked was the non-physical dimension to these spaces [24], as scientists failed to engage with and quantify the practices and traditions associated with these landscapes that enabled the healing process [25]. Similarly, what has not been translated into Western culture is the deep-rooted connection with the land and its relation to self-identity on an everyday basis. The associated values and practices embedded in culture and practice are often the foundation of the healing nature of the therapeutic landscapes. Practices in Indigenous cultures are able to be embodied and translated into everyday places and landscapes.

In fact, only a small portion of the literature on therapeutic landscapes discusses the inclusion of Indigenous methods and the relationship between the environment and health and well-being that most of their spiritual connections are grounded by. However, $80 \%$ of people in developing countries still rely on traditional medicines or methods. They are inexpensive and easily accessible, they are also believed to be stronger and more effective than treatments offered at a healthcare facility [26]. Indigenous methods and practices often combined with everyday health and well-being, mainly when connected to a sense of place and the sense of identity and symbolic healing the environment can enable [24].

This chapter explores therapeutic landscapes and landscape architectural approaches that can be applied to creating or understanding therapeutic landscapes that are culturally and socially responsive. It addresses the gap in the literature regarding therapeutic landscapes to understand how different social and cultural contexts can affect physical, mental, emotional, and spiritual health. Our intent is to illustrate landscapes that include cultural practice and Indigenous healing methods to promote well-being at both individual and community levels. Examining a series of case studies from around the world, it explores landscape architectural responses to healing. The case studies have been selected based on their success in catering to the social, mental, physical and emotional needs of the user. The chapter unpacks the social and cultural contexts that have shaped these environments and discusses how this can be applied to the universal design of everyday therapeutic landscapes.

\section{Method}

To investigate the ideas underlying therapeutic environments, a literature review was undertaken using electronic databases such as Scopus, Google Scholar and ProQuest, as well as landmark book publications. Search terms included therapeutic landscapes, therapeutic environments, healthcare landscapes, and restorative outdoor spaces to identify design criteria. Following the first selection and exclusion of non-relevant materials, twenty-two peer-reviewed publications were evaluated. 
The articles were critically assessed by conducting a strengths and weaknesses analysis of each study and considering their relevance in promoting health and well-being. As causal relationships between therapeutic environments and human health are difficult to establish, this critical literature review focussed on studies that dealt with association rather than causation. To better understand the theoretical constructs and obtain an international perspective of approaches to health and well-being, 32 case studies were initially selected during the scoping of the literature to demonstrate a breadth of scales. To get an understanding of how different places with differing social and cultural contexts responded through their therapeutic environments, samples were selected from five different countries, namely Kopupaka Reserve in Aotearoa-New Zealand, Lions Park in Queensland, Australia, Freedom Park in Pretoria, South Africa, Jiyan Healing Garden, in Chamchamal, Iraq, and Jardín Etnobotánico de Oaxaca in Mexico, for closer investigation.

\section{Kopupaka reserve}

Kopupaka Reserve is a large urban wetland in Auckland, New Zealand. It is unique as it combines an expansive natural environment, which has been identified as having unique healing qualities, with Indigenous Māori cultural values. Māori call themselves the tangata whenua (people of the land), which places importance on the connection between land and sea and respect and preservation of the natural environment and its people [27]. Māori collective cultural orientations brings with them a much more holistic approach to health and well-being, combining sustainable and restorative methods with genealogy (whakapapa).

In an effort to enhance the presence, visibility, and participation with design, a set of design principles for the creation of designed environments were developed based on Māori cultural values [28]. The values that underpin these design framework are rangatiratanga (chieftainship), kotahitanga (unity), kaitiakitanga (guardianship), wairuatanga (spirituality), manaakitanga (hospitality), whanaungatanga (relationship, sense of family connection), and mätauranga (knowledge and wisdom) [29]. Seven principles can be applied to all aspects of design thinking and require an ongoing engagement with Māori tribes. These principles are: mana (status of $i w i$, tribe, and hap $\bar{u}$, sub-tribe, is recognised and respected), whakapapa and mahi toi (Māori names are celebrated by the recognition of traditional place names on signage and wayfinding and cultural landmarks are acknowledged), taiao and mauri-tu (the natural environment is protected, restored and/or enhanced), and mahi toi (Māori narratives are captured and expressed creatively and appropriately) [28].

The Auckland City Council commissioned the Kopupaka Reserve as a new public space for the emerging Westgate shopping centre. The Kopupaka Reseve is an ancestral name for the area and relates to the meeting of the Totara Creek and Waiteputa Stream. The reserve is of a linear shape that follows the riparian corridor of Tōtara Creek and Waiteputa Stream, which had become extremely degraded from the area's long history of growing market produce and most recently a largescale strawberry farm. Once rich with māhinga kai (traditional Māori foods), the waterways had become overloaded with nutrients and infested with weeds. The design restored the native species that once would have grown in the area, including harakeke flax, traditionally used for weaving [28].

Wetland waterways provide an abundance of life with food and purification, contributing to the well-being of the people as Māori maintain that a healthy landscape makes for a healthy individual. Views over the wetlands surrounding the confluence of the two freshwater streams, display the varied birdlife and biologically 
diverse horticulture. Hard landscape forms are inspired by the abundance of kai (food) found in wetlands and guide the boardwalk design (Figure 1). Open spaces for communal activities are contrasted with private places for emotional retreat (Figure 2). The body is engaged through sitting or walking, the senses are engaged through sights, sound and smells. The park is a celebration of the inseparable bond of water and earth. This is deemed vital to sustaining and balancing the natural environment and which is reflected through wairua and which refers to the spiritual plane. Healthy water and rich resources are deeply embedded in Māori cultural and spiritual landscape values as water is sacred.

A distinct and defining feature of the park is a series of interlocked curving timber structures that frame the wetland ponds and a woven together with vegetated paths. The timber frames are a symbolic representation of the hinaki waharua (eel baskets) that were used to collect the tuna (eel) that gathered at one of the historical wetlands in the area [28].

What makes Kopupaka Reserve a successful therapeutic landscape its ability to encourage community engagement and establish a strong sense of place and place identity. These themes are threaded throughout most of the literature that has been written on therapeutic landscapes. As research shifted from its focus on the big event or extraordinary healing spaces to the everyday, the method of healing also shifted from an internal singular process to a communal and inclusive process. Urban park and community gardens emerged as having healing qualities and were celebrated for their unique ability to bring communities together and improve overall well-being. The 22-hectare reserve is located within the centre of Westgate, a new town centre that has emerged as a result of urban sprawl. The park connects together the surrounding suburbs and is a central point for many people. While people are not directly forced to engage with each other or participate in rehabilitative activities, the opportunity is given. Signs and cultural motifs placed around the park tell a narrative of the history of the reserve, people feel more attached to the park as they can understand its significance. The diversity of spaces allows locals to find what they need from the park and offers opportunities to improve their personal health and well-being. The park aimed to restore the mauri (lifeforce) of the area, which was mainly achieved through improved storm water management and the revegetation of key areas improving the water quality of the area and

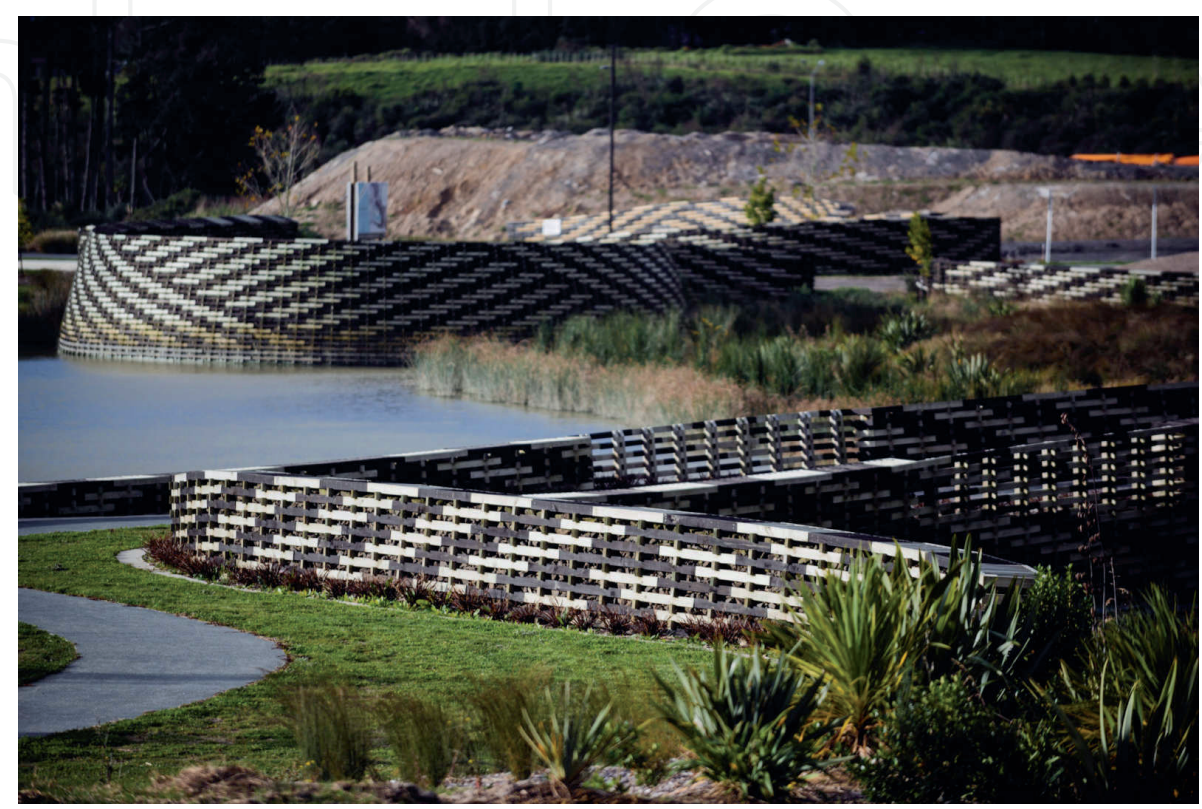

Figure 1.

Kopupaka reserve and the wetlands, where timber frames are deeply inspired in traditional Māori eel baskets. 


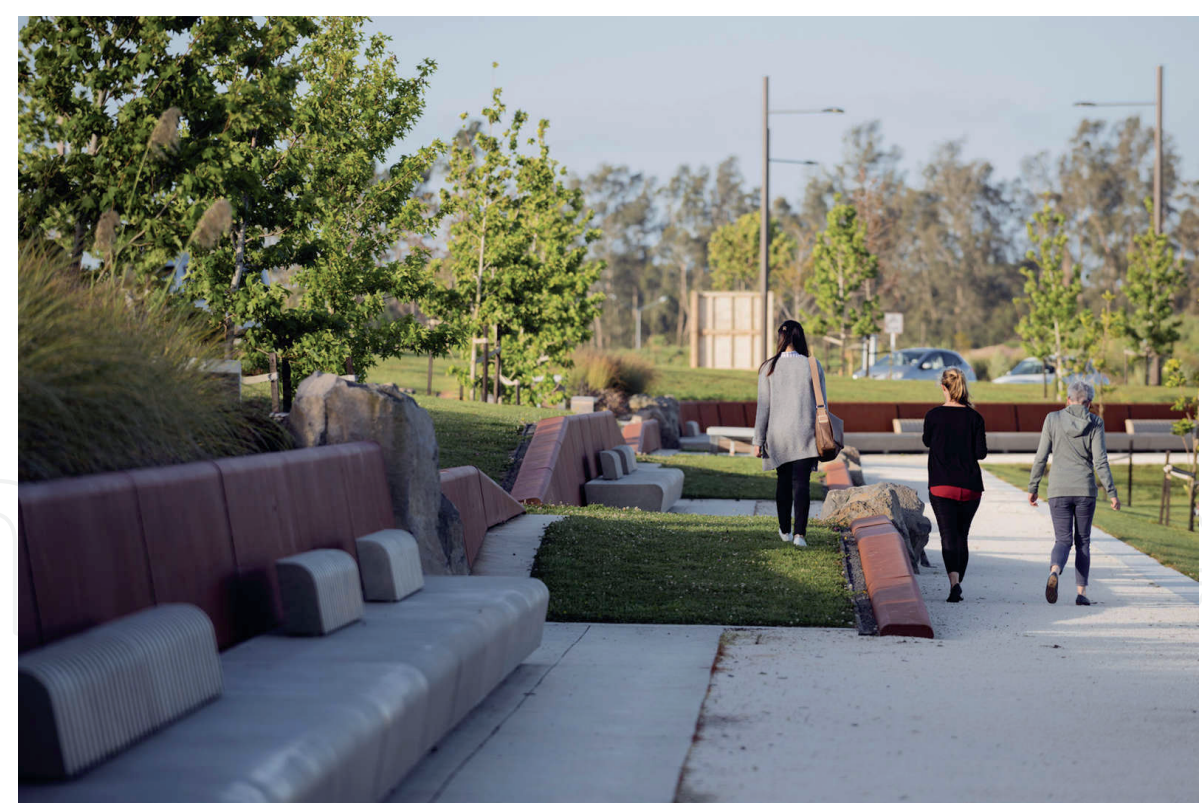

Figure 2.

Recreational activities at Kopupapa reserve.

enhancing habitats and ecological corridors [28]. Kopupaka park demonstrates how urban growth and community engagement can be successfully paired with ecology and engineering [30].

\section{Lions Park}

Lions Park is a small urban park located in Gladstone, Queensland, but in spite of its size, it is considered a revolutionary park for Australia, being one of the first intergenerational and therapeutic environments located within the public realm. It is an inclusive space that has been established for intergenerational socialisation and as a safe space for those with disabilities. Building from the evidence that a strong link exists between the natural environment and improved health and well-being, these spaces provide moments of relaxation, social interaction and physical activity [31]. The park is a destination for locals and it also acts as a thoroughfare between the commercial zone, suburbs and natural environment. The Leonardo Da Vinci inspired playspace incorporates sensory features that can accommodate children and adults with disabilities. The designer, Playscape Creations, worked closely with local communities and those with impairments to create a space that accommodates a diverse range of needs [32]. Due to the urban location, Crime Prevention Through Environmental Design (CPTED) design principles were used throughout the entire design to enhance active and passive surveillance as well as making sure the park was a multi-use space. The increased surveillance also minimises the complexity of maintenance and ensures the park features last longer [32].

The form of the park is inspired by Da Vinci's cogs of interaction. The cogs create islands of play and recreation linked together with wide wheelchair-friendly paths and tactile water features. Each $\operatorname{cog}$ is unique with special elements that engage, inspire, and incorporate user preferences for each impairment. For example, those with sensory processing disorders like to spin and swing, but also enjoy shared play and like spaces to hide away in and just observe from. Those with auditory processing disorders engage well with tactile and visual elements but prefer less busy spaces and bold signage. Those with visual impairments are especially sensitive to light so 
shade is needed along with tactile environments that offer a contrast for navigation. Those with Down syndrome require muscle stimulating equipment, individual and group play opportunities and vestibular play elements. Those with autism can be sensitive to change, so enjoy tactile mapping and colour coding, as well as repetitive play equipment and spaces they can hide away in. For muscular dystrophy, spaces are required to provide shelter from light and heat and have a handhold that can be used with a closed fist. Those with cerebral palsy need rest spaces, handholds that can be used with a closed fist and tactile interactive panels. To accommodate spina bifida, wide wheelchair friendly pathways and transfer points to get on equipment are necessary but also are places for social rest.

Cog one is the entry node at the beginning of the park, which also contains the car park. The purpose of this area is predominantly a gathering space with arranged seating and shelter. From there, the user can move through into the body of the park. Cog two is the linking cog and social hub, connecting either to the nature cog and action cog or the commercial zone cog. In cog three, there is play equipment, informal water play, soft fall mats, turf, and walls that are intended to double as informal seating and shelters. Cog four is the swing, spin and discovery zone and a five-way swing stands in the centre. The play zone is enclosed by a dense vegetation buffer due to its proximity to the road. Cog five is an informal cog dedicated to nature play and exploration play (Figure 3). Activities are less structured in this area and there is more opportunity for imagination to take control [33].

In Lions park, play elements and natural features are thereby designed for all of the seven senses; hearing, sight, smell, touch, vestibular and proprioception. Specific play equipment has been included in the design of the playgrounds to ensure that users of all abilities have been included. These play elements include tactile water features for formal and informal water play, small and large shades for those with heat and light sensitivity, safe havens and small hideaways for those who want to escape, hand hold-on equipment that can be used with a closed fist for those who have limited grip, and spinning and full-body vestibular play features. In addition, consideration has been given to stimulating cognitive, social, psychological and physical senses while in the act of playing on a playground [34]. This playground accommodates a variety of bodily movements that stimulate the mind and body in much the same way as the activity of gardening.

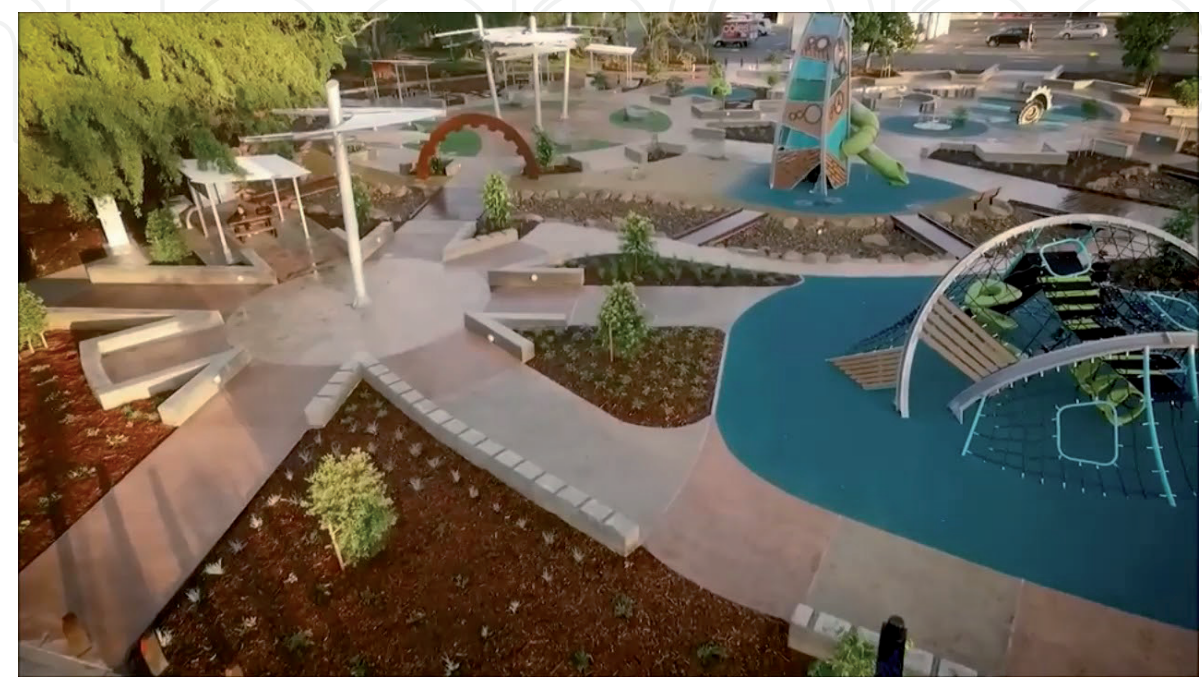

Figure 3.

Lions park and the different cog areas. 


\section{Freedom Park}

Freedom Park is located in one of South Africa's capital cities Pretoria. Situated on the top of a hill overlooking the city of Salvokop, the park was mandated by President Nelson Mandela to communicate a narrative of South Africa's journey to freedom following the end of the apartheid. It is a part of the rebuild seeking to address social fragmentation between races and significant disparities in access to education, health care and employment [35]. Freedom Park is a therapeutic landscape in the form of an urban park that tells a narrative of South Africa's journey to freedom and celebrates the 3.6 billion years of physical change in environment as well as those who fought for its freedom [36].

Freedom Park addresses the physical, mental, spiritual, societal and environmental elements of the landscapes of South Africa and embodies them into one space for all. The park supports South Africa's newfound identity, attempts to create new social networks, and supports the once fractured society. It acknowledges the holistic approach of traditional African culture focusing on the collective and bringing community interests to the forefront of any decisions [37]. One African principle that was not lost with colonialism was 'ubuntu', meaning that 'I am what I am because of who we all are', which follows on from the Zulu saying 'umuntu ngumuntu ngabantu', which means 'a person is a person through other persons' [37]. This principle values people first and foremost with a view of the collective whole [38].

One of the most vital features of the park is its engagement to a sense of place. The development of a sense of place is a social and cultural process that depends upon the user's response and cannot be derived from location alone [39]. Creating a sense of place is affirmed in Freedom Park by the inclusion of the historical narrative and the use of traditional practices. When entering through the //Hapo external space the users make their way through traditional and native medicinal plants. The journey educates the user about traditional practices and sparks conversation (Figure 4). Sense of place is not only an embedded relationship with the natural

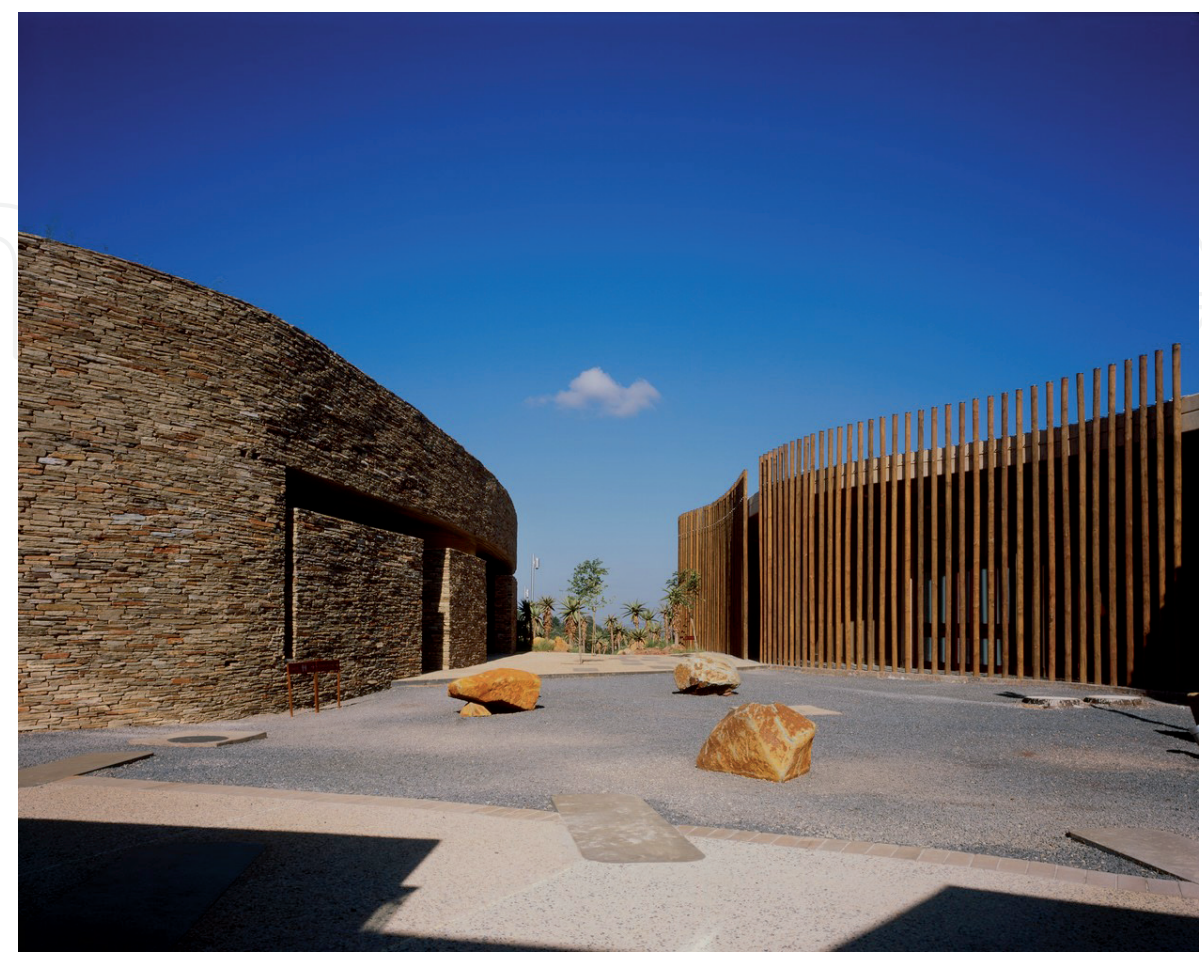

Figure 4 .

Use of traditional materials. 
environment but directly links to the people within the place [39]. The inclusion of the eleven languages around the park aids in establishing place identity. For example, the //Hapo is from the Khoisan language, S'Khumbuto (the memorial) is Swati, Uitspanplek (A picnic area on the northern side of the hill) is an Afrikaans word, and Isivivane is a Zulu word meaning 'to throw your stone upon the pile' [36].

//Hapo is the first point of arrival to the park. This space is an interactive exhibition telling the story of South Africa over the course of 3.6 billion years. The name //Hapo has been drawn from the phrase "//hapo ge//hapo tama/haohasib dis tamas ka i bo', which means 'a dream is not a dream until it is shared by the entire community'. Within //Hapo there are three external spaces. The first space is the Garden of Indigenous Knowledge/the Healing Garden. In this garden, water channels lead visitors into a quiet and contemplative space where they are immersed in medicinal plants and gain knowledge of Indigenous healing methods. The second space is Sentihaga, the children's area. The landscape has been terraced with a series of cascading walls. Children and others are able to play with water features and plant material. Totems, an amphitheatre and small passageways are features of the garden to spark imagination. The third space is called the Boulders. They are metamorphosed layers of rock composed in a circular formation and surrounded by savannah vegetation to tell the story of South Africa's creation. Indigenous vegetation surrounds //Hapo blending the building into the landscape and preserving the natural terrain of the hillside (Figure 5) [36].

Exiting the //Hapo, visitors continue on a contemplative journey up the Salvokop hill along a pathway named the Vhuwaelo. Along the Vhuwaelo there are a series of small gardens that you can weave in and out of, exploring the small private spaces comprised mainly of natural materials and plants. Dramatic views overlook the city of Pretoria and the Union Buildings. At the final moment before you descend down the hill is a space named the Mveledzo. It is made from heavy stones and concrete, providing a final resting spot. Then the visitor descends the hill to arrive at the S'khumbuto, a Swati word for remembering or memorial. The memorial is for those who fought for freedom and showed great leadership. Water has

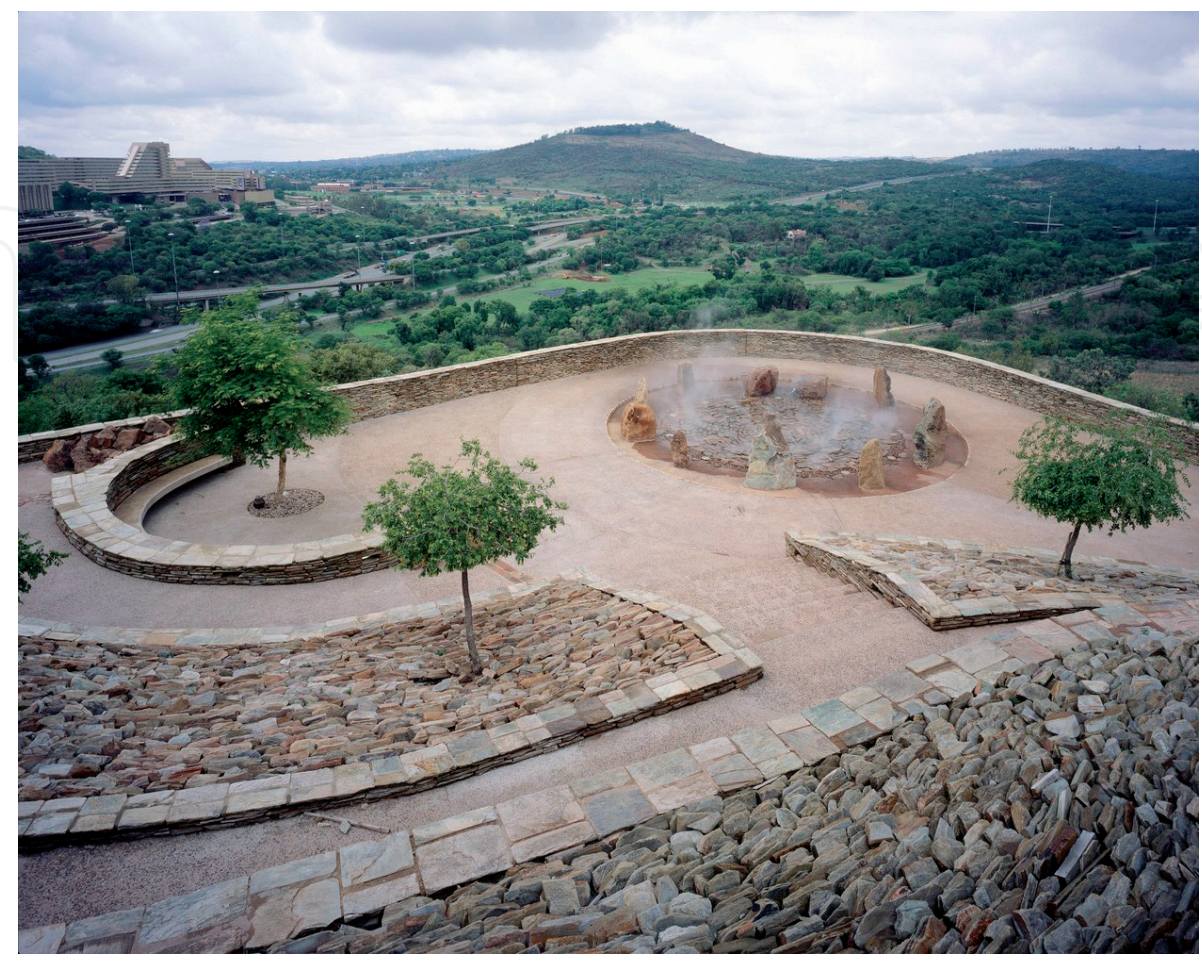

Figure 5 .

Layers of rock surrounded by the savannah vegetation. 
been used throughout the memorial because of its importance to African culture and its relation to healing and purification [36].

\section{Jiyan healing garden}

The Jiyan Healing Garden is a treatment facility and therapeutic garden that was established by the Jiyan Foundation for Human Rights in Chamchamal, Iraq in 2016. The Jiyan Foundation began its work in 2005 by building rehabilitation centres throughout Kurdistan and Iraq for those who were survivors of torture. The healing garden is an animal-assisted trauma therapy centre for those who suffered at the hands of Saddam Hussein's regime and, more recently ISIS. Many children in Iraq suffer from problems associated with this trauma, including behavioural and speech disorders.

A crumbling public infrastructure, including the water and sanitation network, results from years of political unrest. The Jiyan Foundation for Human rights wanted to create a space that was self-sustaining and supported the surrounding environment. The team of architects worked in collaboration with BORDA (Bremen Overseas Research and Development Association) to create a decentralised wastewater system for the garden [40]. This was deemed necessary as the Kurdistan region continually suffers from a rainfall deficit and low groundwater levels. The decentralised wastewater treatment system taps into the sewage pipes that run under the facility and is able to clean 100 cubic meters of dirty water each day, enough water to provide the entire garden with water. The water system also processes animal and human waste, turning it into biogas used for heating the therapy rooms in the winter [41].

ZRS, the architects of the treatment facility and healing garden, wanted to create a space that represented trust, identity and well-being. The facility is an example of traditional and sustainable architecture. The buildings are constructed from local clay material that has been historically used in the area (Figure 6). The walls are built from the air-dried brick blended with the thin layer of earth-straw mix. The roof is also constructed from the thin earth straw mix. The earth materials have climate cooling properties that concrete and glass cannot provide. The earth keeps

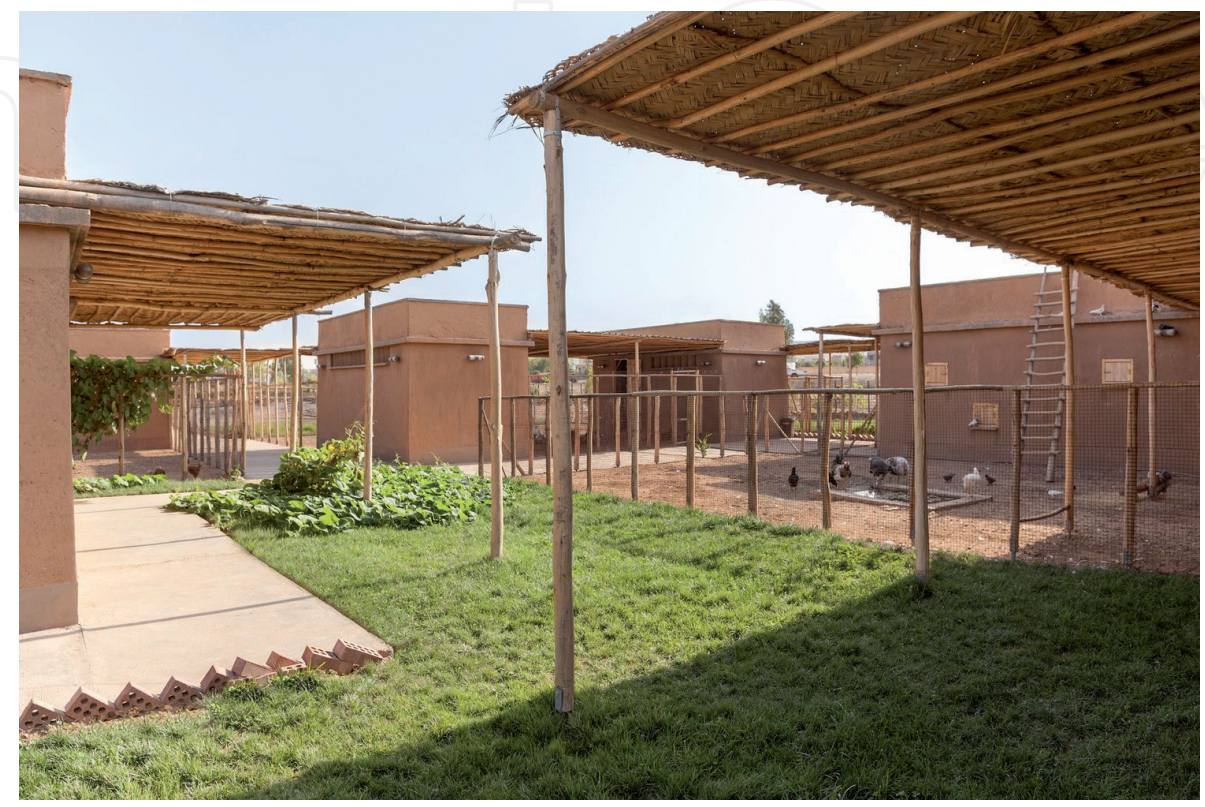

Figure 6.

Illustration of the building's layout and materials used. 
the interior space cool during the hot summers and then keeps the interior dry and warm during the wet and sharp winter months [42].

The treatment facility is situated in a recreated traditional village environment typical to that in Chamchamal. In total, there are 11 individual dwellings that provide therapy rooms and quiet spaces that users can retreat to. A courtyard and shade device connect the dwellings together and allow access to the central healing garden and the animal pens. The garden and buildings create a unique space to heal and the garden is full and flourishing compared to the barren terrain of Chamchamal. Those at the facility participate in group-based garden therapy, which gives them a support network and a new way to overcome their ordeal [42]. The treatment facility also allows them to participate in group activities in the garden and direct therapeutic work in the huts. The technique they tend to use with the children is 'mud therapy'. The kids are encouraged to play outside in the garden and in the mud. They are prompted to get dirty and interact with the many animals before coming back inside for a discussion when they feel safe and comfortable and are often more willing to open up (Figure 7) [40].

A distinguishing feature of this therapeutic landscape is the animal-assisted therapy. Those who have been subject to trauma caused by acts of war, torture, violence, or displacement have strong feelings of vulnerability. They are often automatically and subconsciously drawn to the animals. They will try to get close to the animals to feel safe and comfortable. It is also said that the practice of petting, brushing, walking and caring for the animals helps give people something else to focus on, increases self-esteem and reduces feelings of anxiety, grief and isolation. The animals introduced to the Jiyan Healing Garden are a mixture of local animals that many would find in the area as well as exotic animals. Those who use the facility have been subject to generations of pent up trauma and psychological abuse and most are having to adjust to a new life away from their home and loved ones.

The Jiyan Healing Garden adopts place-making strategies and familiarisation through structured individual and communal activities making this space an internationally award winning 'therapeutic landscape'. The gardens provide relief and help to those who are suffering trauma from torture and acts of war and it gives the community access to adequate green space [40]. Green space that is inclusive and contains structured activities is crucial for creating stronger and resilient communities. This is the grounding essence of a therapeutic landscape.

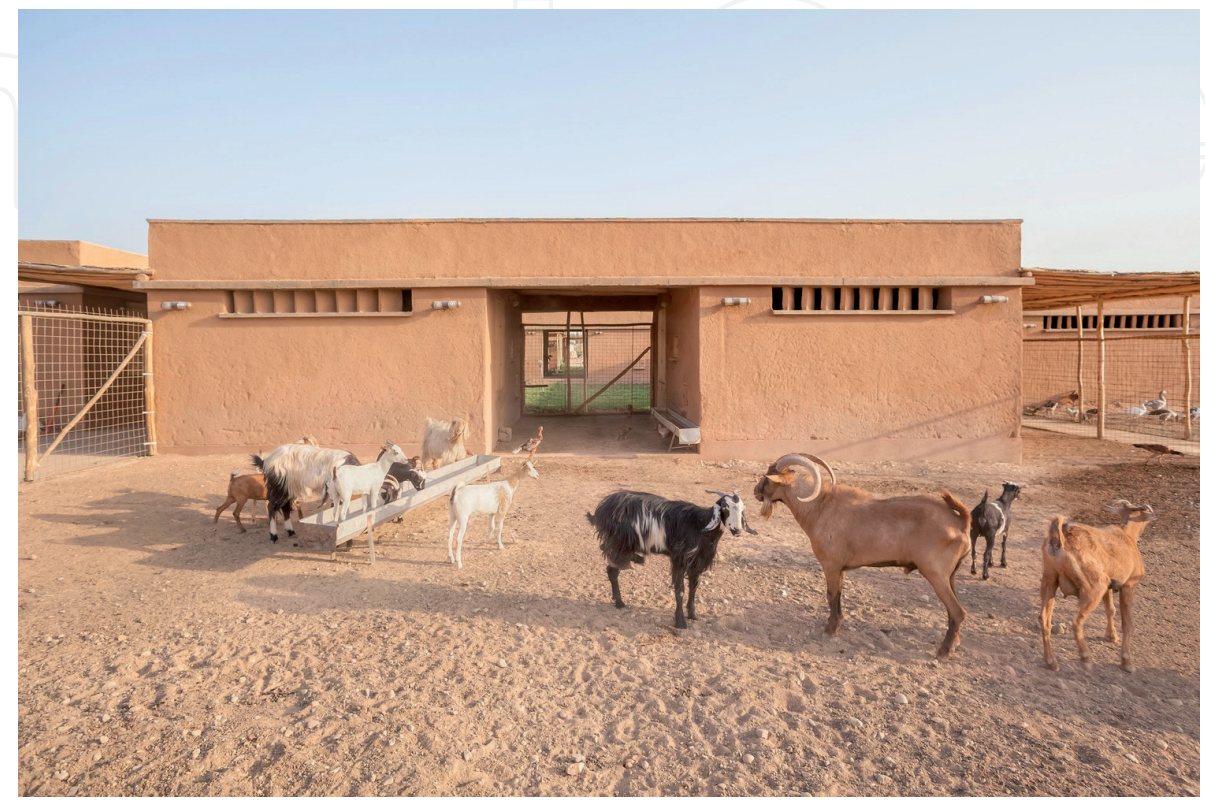

Figure 7 .

Outdoor spaces and access to interact with animals. 


\section{Jardín Etnobotánico de Oaxaca}

Jardín Etnobotánico de Oaxaca is deemed one of the world's most original public botanic gardens, it is an ethnobotanical garden on the grounds of the San Domingo monastery in Oaxaca Mexico. Mexico is one of the most biologically rich countries globally, and out of the 31 states in Mexico, Oaxaca is the most biodiverse. Oaxaca has a unique botanical history as it contains evidence of plant domestication of squash and corn in the Americas dating back to the beginning of the new world. The ethnobotanical garden has been designed to reflect and celebrate this unique diversity. Each section of the garden displays a different ecology. The northeast section of the garden is dedicated to the tropical forest. Species that have been included in this section are balsa, ceiba and huaie. The east section of the garden reflects the wet regions of Oaxaca, including species of cacao, vanilla and achiote. The west of the garden is dedicated to the dry lands and includes plant varieties; cacti and agaves [43]. A planter bed planted with squash has been raised above the rest of the garden and faces towards Guilá Naquitz [43].

The garden tells a strong narrative of the natural history of Mexico, as well as exploring the cultural and artistic traditions of Oaxaca. During the site excavation, structures more than 400 years old were discovered and incorporated into the final design. A number of other artists, scientists, anthropologists and horticulturalists collaborated on the design of the planting, hardscape and water systems [43]. The use of materials and hardscaping is unique to the garden and emphasises the narrative of Oaxaca's history (Figure 8). A distinct feature of the garden is the green-hued pathway that mimics the formation of a step-fret zigzag. This pattern is common in many pieces of pre-Columbian carving and art. Another distinct feature of the garden is a large water fountain that seeps a distinct red water. The fountain is made from the wood of the Montezuma cypress tree and the water has been dyed red from ground up cochineal coating the wood [43].

The designers and director of the garden choose to include minimal signage around the garden to allow for a more seamless aesthetic. Visitors who want to get a richer experience of the garden and learn about the specific varieties of plant

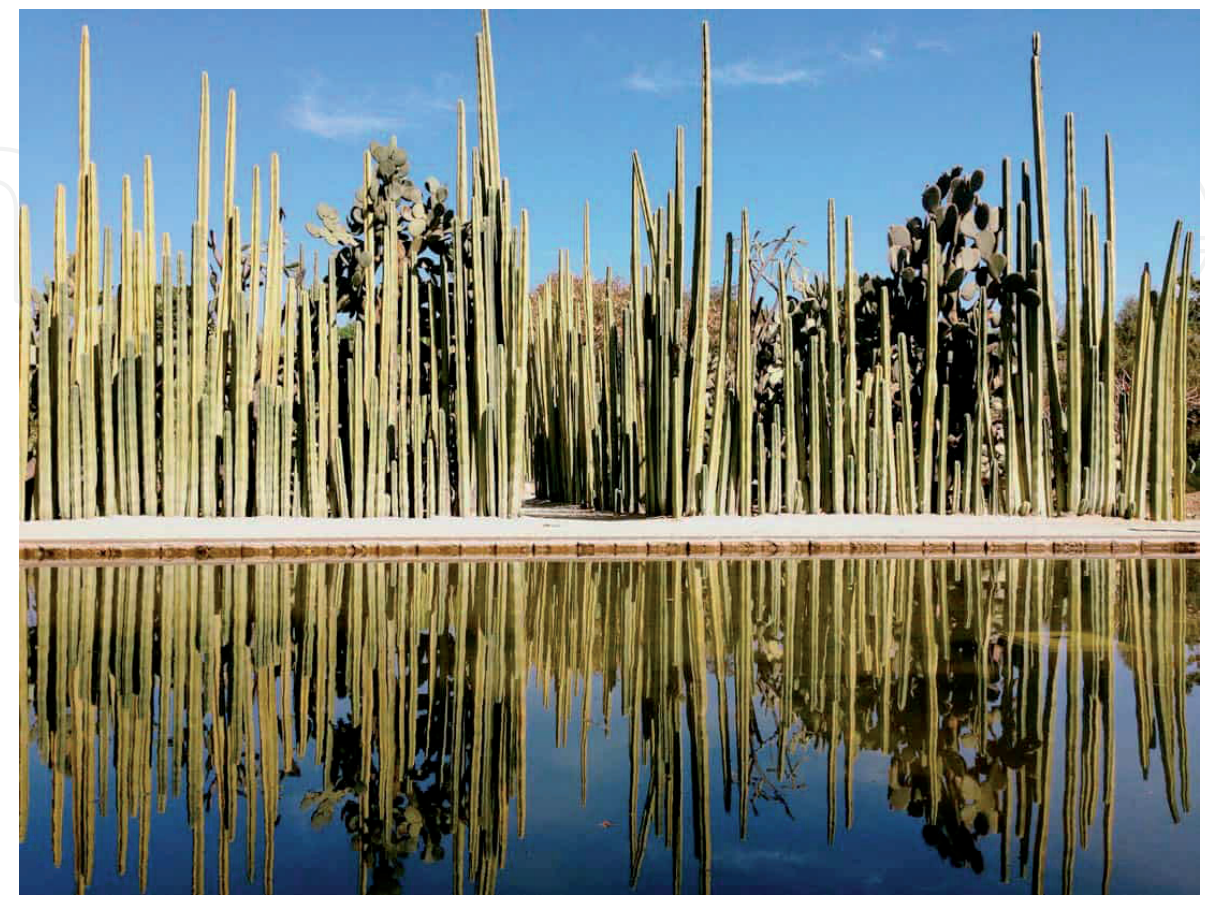

Figure 8.

Use of softscape and hardscape materials typical to Oaxaca. 


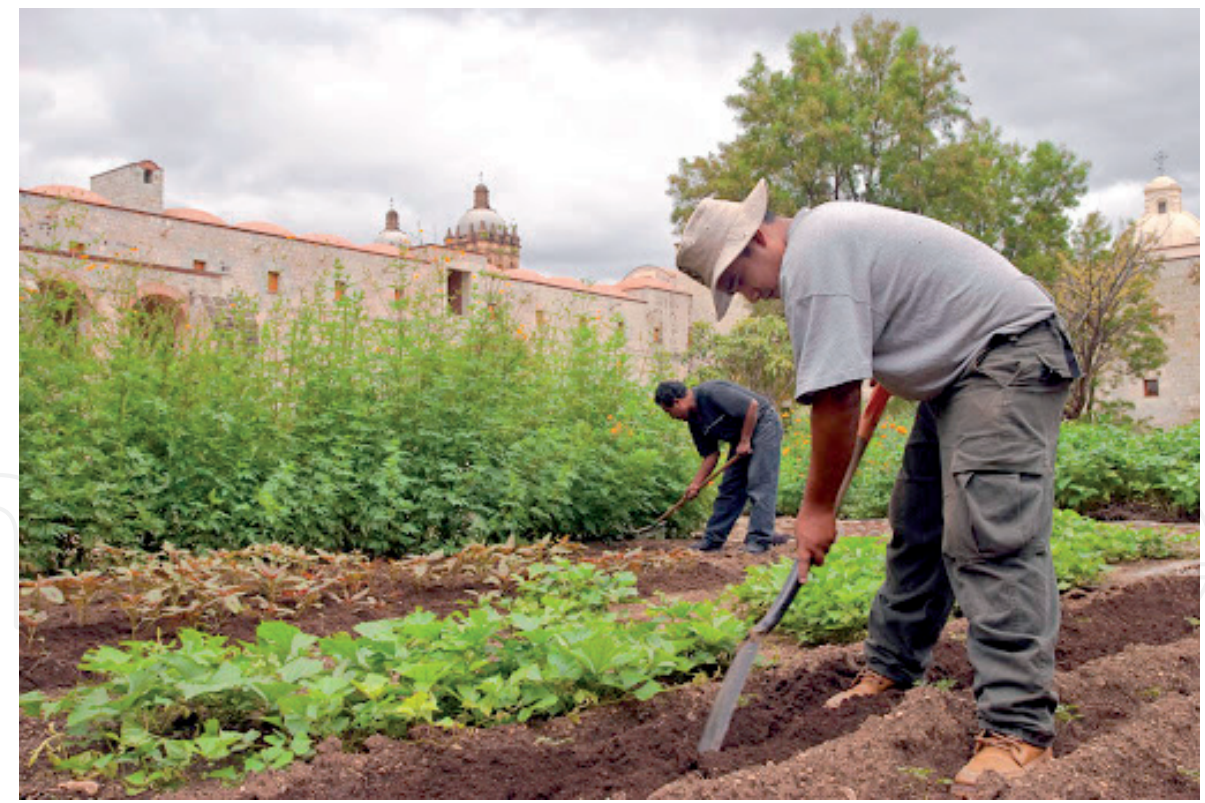

Figure 9.

Horticultural practices at the site.

species are encouraged to take a 2-hour tour. During this tour, they are taken through the medicinal and ceremonial plants, including mesquite, copal used in incense, alebriies for carving, and agave plants traditionally used to make mezcal. Visitors are also taken through a section of the garden that is dedicated solely to traditional food crops. The crops include hierba de conejo, corn, beans, chepil (the herb used in tamal de chepil), jicama, amaranth, tomatoes, and chia. Many of these plants were domesticated in Oaxaca. Although, there are around 1000 different varieties of plants in the garden, they are all wild except for the traditional food crops (Figure 9) [44].

What makes this space a successful therapeutic environment is the strong sense of place that is created by place attachment and narratives. There are many repetitive and empowering cultural and historical motifs that feature in the garden and speak to Oaxaca's history as one of the more important sites of archaeological history for the Americas, showing the first signs of plant domestication [43]. In the 1970s, seeds of squash, bottle gourd, beans, agave, and chilli peppers were all excavated and included in the ethnobotanical garden design [44]. Visitors to the garden and locals can learn about the ancient history of Oaxaca and the rest of the Americas to understand the role the area played in the development of the new world, creating a strong sense of place identity. But what is also successful about this place is that it began as a passion project from the many locals in the community who wanted to see the preservation of art, culture and the environment. This developed into the current ethnobotanical garden that allows the community to explore the relationship between plants and people and work in harmony with the Cultural Centre. Local designers, artists, scientists, horticulturists, and anthropologists all worked together on the design, construction and infrastructure within the garden. As such, this 'community' garden provides unique opportunities to participate in communal activity and interaction.

\section{Discussion}

Successful therapeutic landscapes address the social and cultural contexts of their location as well as respond to the environmental, mental and physical needs 
of each user. In defining therapeutic environments as reliant on a series of encounters, networks, and associations, Duff [16] classified these enabling resources into three categories: social, affective, and material. Social resources are grounded in relationships but are also directly linked to place, since they are a product of it and simultaneously enable everyday experiences. Affective resources are the fusion of individual or collective feelings that define or restrict orientations or actions. Material resources characterise the way in which relationships are established through the materiality of place and how they impact our access to goods, services, and information. Therapeutic landscapes can strengthen and improve the overall well-being of an individual, a community or even a population. In the case studies, a variety of processes were used to foster therapeutic environments, bringing together the relational, affective, emotional and cognitive skills that create and maintain social networks and promote meaningful experiences, closely weaving together land, culture and health.

\subsection{The land}

Landscapes are experienced in different ways by different people. Different cultural orientations may also lead to different experiences of the same space; however, this does not negate its therapeutic qualities. Similarly, the experience of therapeutic landscapes will vary based on previous experiences or attachments. In the literature, sense of place is discussed as being related to the inclusivity of the design and the intention of the user, but it can also refer to the historical connection with the space, which can enrich the 'place identity'. Placemaking enables the restorative and healing abilities of therapeutic landscapes, aiding those seeking the social inclusion or home comfort and attachment that is often formed through activities and the communal associations made [39]. The spaces that were the most successful in creating a holistic healing landscape for the community, were those environments that were welcoming and established a strong sense of place for all users. Hereby, the sense of place in a therapeutic landscape can result from place identity and place attachment and is often felt by a user when they have an emotional or historical connection to that place.

Two case studies, in particular, illustrate how the land grounds the therapeutic nature of the place. The Kopupaka Reserve in Aoteroa-New Zealand guides visitors along constructed boardwalks. The surrounding waterways provide an abundance of life with views over the wetlands and freshwater streams to the varied birdlife and biologically-diverse horticulture. Open spaces for communal activities are contrasted with private places for emotional retreat, providing a human experience that engages with all the senses through sight, sound and smell. With the attention shift from intimate perspectives to distance views, the approach also changes from a very singular and internal healing process to a communal and inclusive one. The design is permeable and flexible, allowing the materials to flex with the movement of the land and using materiality to will enable the ecology to flow.

Freedom Park in South Africa also uses the land to bring people together. One of the strongest features of this park is its engagement with the sense of place. Bringing together formerly alienated groups in a neutral landscape that offers both distant views over a cityscape and intimate pocket spaces, it is concerned with the physical, mental, spiritual, societal and environmental landscapes of South Africa, embodying them into one space for all. Emotions typically run high when the historical injustices of apartheid are situated in a specific place. The park is designed to seamlessly disappear into its natural context as the materiality of the built environment emulates and draws inspiration from the surrounding nature. 


\subsection{Culture}

Therapeutic landscapes can provide an opportunity to embed cultural and traditional practices that do not often get conveyed in everyday contexts. For example, the Jardín Etnobotánico de Oaxaca (Mexico) began as a passion project for many locals in the community who wanted to see the preservation of art, culture and the environment. The garden tells a story about the cultural and artistic traditions of Oaxaca as well as its place in the natural history of Mexico. There are many repetitive and empowering cultural and historical motifs that feature in the garden and speak to Oaxaca's history. From a social perspective, it brings together artists, horticulturalists, scientists and anthropologists as well as the community at large to reflect the purpose of the garden as an exploration of the relationship between plants and people. The use of materials and hardscaping is also unique to the garden and emphasises the specific narrative of Oaxaca's history. In this project, the health of individuals reflects the strength of the community and collective triumphs are celebrated over the personal gains of the individual.

Another important example of a successful therapeutic environment that celebrates cultural values and includes Indigenous and traditional materials and practices within the design of the landscape is the Kopupaka Reserve (New Zealand). Importance was given to creating a place identity and understanding of how the land was used pre-colonisation. The New Zealand case study adopted a series of principles, Te Aranga framework, to ensure a cultural approach was taken to design that encouraged designers to engage with local Māori tribes in all aspects of the design and construction processes and to ensure that plants and materials had been chosen correctly. Cultural values hereby affect and maintain physical, emotional, mental and spiritual health and well-being. Our findings align with those of Andrews [17], whereby a successful therapeutic landscape has been shaped by the influence of a belief system/culture and emotionally engages with human experience. If these are embedded within the design, the environment will inherently respond to the needs of each individual user in a holistic sense and provide the foundation for a more affluent, healthier lifestyle. For many, connection through place or land includes not just the individual but the entire community of beings, living and non-living, putting the need for connection at the forefront.

\subsection{Health}

The literature review highlighted some clear themes relating to health that are thread throughout the discussion of therapeutic landscapes and what a successful holistic healing space should provide. Therapeutic environments and healing environments need to be designed to the needs of the user; which includes the needs of the marginalised. Two landscapes that are specifically designed for unique human experience are the Jiyan Healing Garden (Iraq) and Lions Park (Australia).

In the Jiyan Healing Garden, the healing garden is designed for victims of trauma and to address the social tensions that had widened the gap between the places of emotional retreat and healing from those of everyday sociability. Here the healing garden serves as an emotional retreat that facilitates an 'extraordinary' healing experience. For this reason, it takes a unique approach and involves access to animal therapy and pays attention to the specific needs of the user. In addition, it offers the chance for patients to work on the upkeep of a garden actively, activities they may have done at home [23]. Participation at this level creates a sense of ownership and sense of place in the facility, improving the productivity of healing and rehabilitation. Wellness and health of a community do not rely solely on the physical gains from gardening but also the mental gains. Feelings of loneliness 
and isolation can be mitigated by involvement in communal gardening as well as the practice of plant propagation and cultivation [34]. Concerning the material, a diverse range of spaces and activities are essential to the inclusivity of a space. For this garden, the choice of plants was vital, which targeted the user and their preferred activities [23]. While the garden's main intention is to provide relief and help those suffering trauma from torture and acts of war, it also gives the community access to adequate green space. Green spaces that are inclusive and contain structured activities are crucial for creating more robust and resilient communities. This is the grounding essence of a therapeutic landscape.

Similarly, the Lions Park (Queensland, Australia) has been designed for participation and socialisation on a much smaller scale. With its design focus on intergenerational socialisation and inclusion for those with disabilities, interactive areas provide for various body movements that include vestibular and proprioception and sound, sight, smell, and touch. Social inclusion is achieved through the creation of spaces that meet the needs and desires of all potential users. There are also spaces of refuge that can be used to hide away, for relaxation or contemplation. Playgrounds provide various bodily movements that stimulate the mind and body, similar to the activity of gardening. In particular, play equipment was included within the design of the playground to ensure that users of all abilities were included. Wheelchairfriendly paths, shelters for those who are light-sensitive, tactile panels, visually stimulating signs and planting combinations all combine to create an inclusive and restoratively productive environment.

\section{Conclusion}

Our understanding of what makes up a therapeutic landscape is evolving. Social issues including; quality of life, access to health care, social inclusion and supportive environments were all addressed in most literature, but overall, we found a lack of engagement with the important cultural context of the therapeutic landscapes and in particular, the inclusion of Indigenous practices. Our research finds that Indigenous methods can provide a holistic approach to health and well-being in our communities and a finer grained understanding of a therapeutic environment.

Our case studies varied in scale from large and expansive natural landscapes to small manmade interventions, but all shared social inclusion as a recurrent theme and all acknowledged aspects of land, culture and health. The successful therapeutic environments were tied to the inclusivity of the design and the intention of the users, but also the historical connection to enrich the place identity. Most of these spaces have come about as projects as a response to passion and request from the local community or as a response to social or cultural demands. This has resulted in the inclusion of the community's needs in the designed spaces and their physical input in the landscape.

The concept of therapeutic landscapes has evolved with research and theory to reflect society's current values. Most recently, this has shifted with the desire to have healthy and strong communities. A stronger sense of place is considered to create stronger communities and improved community-wide health and well-being. The success of a community cannot be separated from the success of its place, including the natural settings, the local culture and wider surroundings. In this way weaving land, culture and health is essential to the concept of the therapeutic environment.

\section{Conflict of interest}

The authors declare no conflict of interest. 

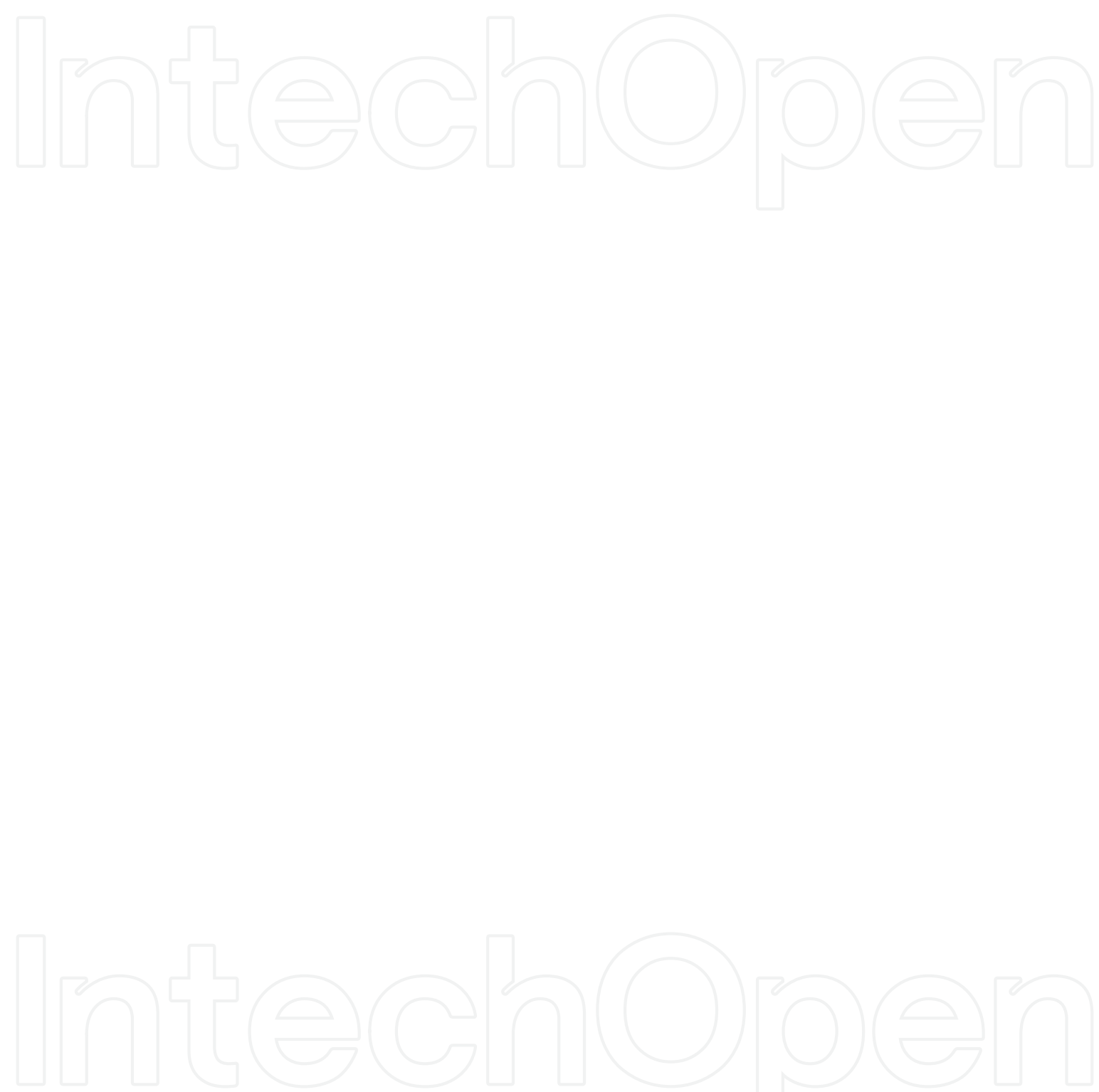

\section{Author details}

Bruno Marques*, Jacqueline McIntosh and Hayley Webber Wellington School of Architecture, Victoria University of Wellington, Wellington, New Zealand

*Address all correspondence to: bruno.marques@vuw.ac.nz

\section{IntechOpen}

(C) 2021 The Author(s). Licensee IntechOpen. This chapter is distributed under the terms of the Creative Commons Attribution License (http://creativecommons.org/licenses/ by/3.0), which permits unrestricted use, distribution, and reproduction in any medium, provided the original work is properly cited. (cc) BY 


\section{References}

[1] Bell SL, Foley R, Houghton F, Maddrell A, Williams AM. From therapeutic landscapes to healthy spaces, places and practices: A scoping review. Social science $\&$ medicine. 2018;196:123-130.

[2] Kaplan R, Kaplan S. The experience of nature: A psychological perspective. Cambridge University Press; 1989. 152 p.

[3] Ugolini F, Massetti L, Calaza-Martínez P, Cariñanos P, Dobbs C, Ostoić SK, Marin AM, Pearlmutter D, Saaroni H, Šaulienė I, Simoneti M. Effects of the COVID-19 pandemic on the use and perceptions of urban green space: An international exploratory study. Urban forestry \& urban greening. 2020;56:126888.

[4] Honey-Rosés J, Anguelovski I, Chireh VK, Daher C, Konijnendijk van den Bosch C, Litt JS, Mawani V, McCall MK, Orellana A, Oscilowicz E, Sánchez U. The impact of COVID-19 on public space: an early review of the emerging questions-design, perceptions and inequities. Cities \& Health. 2020:1-7.

[5] Thompson CW. Linking landscape and health: The recurring theme. Landscape and urban planning. 2011;99(3-4):187-195.

[6] Marques B, McIntosh J, Hatton W. Haumanu ipukarea, ki uta ki tai:(re) connecting to landscape and reviving the sense of belonging for health and wellbeing. Cities $\&$ health.

2018;2(1):82-90.

[7] Marques B, McIntosh J, Kershaw C. Therapeutic environments as a catalyst for health, well-being and social equity. Landscape Research. 2021;19:1-6.

[8] Ulrich R, Gilpin L. Healing arts. Nursing. 1999;4(3):128-133.
[9] Stigsdotter U, Grahn P. What makes a garden a healing garden. Journal of therapeutic Horticulture. 2002;13(2): 60-69.

[10] Gesler WM. Therapeutic landscapes: medical issues in light of the new cultural geography. Social science \& medicine. 1992;34(7):735-746.

[11] Smyth F. Medical geography: therapeutic places, spaces and networks. Progress in Human Geography. 2005;29(4):488-495.

[12] Conradson D. Landscape, care and the relational self: therapeutic encounters in rural England. Health \& place. 2005;11(4):337-348.

[13] Dunkley CM. A therapeutic taskscape: Theorizing place-making, discipline and care at a camp for troubled youth. Health \& place. 2009;15(1):88-96.

[14] Gatrell AC. Therapeutic mobilities: walking and 'steps' to wellbeing and health. Health \& place. 2013;22:98-106.

[15] Foley R. Performing health in place: The holy well as a therapeutic assemblage. Health \& place. 2011;17(2):470-479.

[16] Duff C. Networks, resources and agencies: On the character and production of enabling places. Health \& place. 2011;17(1):149-156.

[17] Andrews, G. Landscapes of Wellbeing. In: Brown T, Andrews G J, Cummins S, Greenhough B, Lewis D, Power A, editors. Health geographies: A critical introduction. London: John Wiley \& Sons; 2017. p. 59-74.

[18] Bingley, A. Health, People and Forests. In: Convery I, Corsane G, Davis P, editors. Making Sense of Place: 
Multidisciplinary Perspectives. Boydell and Brewer; 2012. p. 107-116.

[19] Khachatourians AK. Therapeutic landscapes: A critical analysis [Doctoral dissertation]. Department of Geography: Simon Fraser University; 2006.

[20] Williams A. Therapeutic landscapes as health promoting places. A companion to health and medical geography. 2010:207-223.

[21] Foley R, Kistemann T. Blue space geographies: Enabling health in place. Health \& place. 2015;35:157-165.

[22] Foley R, Wheeler A, Kearns R. Selling the colonial spa town: The contested therapeutic landscapes of Lisdoonvarna and Te Aroha. Irish geography. 2011;44(2-3):151-172.

[23] Mei C. Planting design and its impact on efficacy in therapeutic garden design for dementia patients in longterm care facilities in North Texas [Doctoral dissertation]. The University of Texas at Arlington; 2012.

[24] Wilson K. Therapeutic landscapes and First Nations peoples: an exploration of culture, health and place. Health \& place. 2003;9(2):83-93.

[25] Bell SL, Phoenix C, Lovell R, Wheeler BW. Seeking everyday wellbeing: The coast as a therapeutic landscape. Social Science \& Medicine. 2015;142:56-67.

[26] Gold CL, Clapp RA. Negotiating health and identity: Lay healing, medicinal plants, and indigenous healthscapes in highland Peru. Latin American Research Review. 2011; 93-111.

[27] Marques B, McIntosh J, Hatton W, Shanahan D. Bicultural landscapes and ecological restoration in the compact city: The case of Zealandia as a sustainable ecosanctuary. Journal of Landscape Architecture. 2019;14(1): 44-53.

[28] Auckland Design Manual. Kopupaka Reserve Wetland Park [Internet]. 2017. Available from: http://content. aucklanddesignmanual.co.nz/resources/ case-studies/kopupakareserve/ Documents/Kopupaka\%20Case\%20 Study.pdf [Accessed: 2020-11-17]

[29] Jacqueline Paul. Exploring Te Aranga Design Principles in Tāmaki. National Science Challenges Building Better Homes, Towns and Cities Ko ngā wā kāinga hei whakamāhorahora [Internet]. 2017. Available from: https:// www.buildingbetter.nz/publications/ urban_wellbeing/Paul_2017_exploring_ te_aranga_design_principles.pdf [Accessed: 2021-04-12]

[30] Isthmus. Kopupaka Park, Landezine [Internet]. 2017. Available from: http:// www.landezine.com/index. php/2017/04/kopupaka-park-byisthmus-group/ [Accessed: 2021-03-21].

[31] Carter M. Wetlands and health: how do urban wetlands contribute to community wellbeing?. In: Finlayson C, Horwitz P, Weinstein P, editors.

Wetlands and human health. Dordrecht: Springer; 2015. p. 149-167.

[32] Playscape Creations. Lions Park, Gladstone [Internet]. 2017. Available from: https://www.playscapecreations. com.au/lions-park-gladstone/

[Accessed: 2021-04-04]

[33] Gladstone Council. Lions Park, Gladstone [Internet]. 2017. Available from: https://www.gladstone.qld.gov.au/ parks [Accessed: 2021-04-04].

[34] Ferrini F. Horticultural therapy and its effect on people's health. Advances in Horticultural Science. 2003;77-87. 
[35] Curtis N. South Africa: The Politics of Fragmentation. Foreign Affairs. 1972;50(2):283-296.

[36] GREENinc, The Freedom Park by GREENinc, Landezine [Internet]. 2012. Available from: http://landezine.com/ index.php/2012/09/the-freedom-parkby-greeninc/ [Accessed: 2021-04-11].

[37] Maluleke MJ. Culture, tradition, custom, law and gender equality. Potchefstroom Electronic Law Journal/ Potchefstroomse Elektroniese Regsblad. 2012;15(1).

[38] Gade CB. The historical development of the written discourses on ubuntu. South African Journal of Philosophy. 2011;30(3):303-329.

[39] Lynch KA. The land tells our story: urban native place-making and implications for wellness [Doctoral dissertation]. Boston University; 2016.

[40] Alex MacDonald. Kurdistan 'healing garden' aims to help Iraqis deal with trauma, Middle East Eye [Internet]. 2017. Available from: https:// www.middleeasteye.net/news/ kurdistan-healing-garden-aims-helpiraqis-deal-trauma [Accessed: 2021-05-10].

[41] BORDA. Nothern Iraq: building a Healing Garden with a sustainable water supply, BORDA WesCA [Internet]. 2018. Available from: https://bordawesca.org/healing-garden-providing-asustainable-water-supply/ [Accessed: 2021-04-28].

[42] ZRS Architekten Ingenieure. Jiyan Healing Garden / ZRS Architekten Ingenieure, Archdaily [Internet]. 2017. Available from: https://www.archdaily. com/883358/jiyan-healing-garden-zrsarchitekten-ingenieure [Accessed:

2021-03-22].

[43] Jeff Spurier. Oaxaca's

Ethnobotancial Garden, Garden Design
[Internet]. 2011. Available from: https:// www.gardendesign.com/mexico/ oaxaca-ethnobotanical.html [Accessed: 2021-03-25].

[44] Rebecca Bailey. Jardín Etnobotánico de Oaxaca, Que Pasa Oaxaca [Internet]. 2018. Available from: http://www. quepasaoaxaca.com/jardinetnobotanico-de-oaxaca/ [Accessed: 2021-03-26]. 